\title{
Electrochemical Investigation of Carbon as Additive to the Negative Electrode of Lead-Acid Battery
}

\author{
Matthew M. Fernandez ${ }^{a}$, Francis M. Mulimbayan ${ }^{b}$, and Manolo G. Mena ${ }^{c}$ \\ Department of Mining, Metallurgical, and Materials Engineering, University of the Philippines, Diliman, Quezon City, Philippines
}

\begin{abstract}
The increasing demand of cycle life performance of Pb-acid batteries requires the improvement of the negative $\mathrm{Pb}$ electrode's charge capacity. Electrochemical investigations were performed on $\mathrm{Pb}$ electrode and $\mathrm{Pb}+$ Carbon (Carbon black and Graphite) electrodes to evaluate the ability of the additives to enhance the electrochemical faradaic reactions that occur during the cycle of $\mathrm{Pb}$-acid battery negative electrode. The electrodes were characterized through Cyclic Voltammetry (CV), Potentiodynamic Polarization (PP), and Electrochemical Impedance Spectroscopy (EIS). CV revealed that the addition of carbon on the Pb electrode increased anodic and cathodicreactions by tenfold. The kinetics of $\mathrm{PbSO} 4$ passivation measured through PPrevealed that the addition of Carbon on the $\mathrm{Pb}$ electrode accelerated the oxide formation by tenfold magnitude. The Nyquist plot measured through EIS suggest that the electrochemical mechanism and reaction kinetics is under charge-transfer. From the equivalent circuit and physical model, $\mathrm{Pb}+\mathrm{CB} 1$ electrode has the lowest EIS parameters while $\mathrm{Pb}+\mathrm{G}$ has the highest which is attributed to faster faradaic reaction. The Nyquist plot of the passivated $\mathrm{Pb}+\mathrm{CB} 1$ electrode showed double semicircular shape. The first layer represents to the bulk passive $\mathrm{PbSO} 4$ layer and the second layer represents the Carbon+PbSO4 layer. The enhancements upon addition of carbon on the $\mathrm{Pb}$ electrode were attributed to the additive's electrical conductivity and total surface area. The electrochemical active sites for the $\mathrm{PbSO} 4$ to nucleate and spread increases upon addition of electrical conductive and high surface area carbon additives.
\end{abstract}

\section{Introduction}

The increasing demand of cycle life performance of Lead-acid ( $\mathrm{Pb}$-acid) batteries requires the improvement of the negative lead electrode [1]. One application is for new generation transportation vehicles such as Hybrid Electric Vehicles (HEV), at which the $\mathrm{Pb}$-acid battery requires continuous operation and being able to accept charge and discharge at extreme high rates [2, 3]. During the discharge of a $\mathrm{Pb}$-acid battery, the negative electrode reacts with the sulfuric acid ( $\mathrm{H} 2 \mathrm{SO} 4)$ electrolyte to form non conducting lead sulfate (PbSO4) [4]. The buildup of $\mathrm{PbSO} 4$ at the negative electrode during the repeated cycle of charge and discharge of the Pb-acid battery is deleterious to its operational life due to decreased electronic conductivity and reduced active sites. The negative electrode of $\mathrm{Pb}$-acid battery were perceived as the life-limiting component as the accumulation of $\mathrm{PbSO} 4$ becomes thicker with further cycling which leads to reduction of capacity and premature failure $[4,5]$.

The negative electrode performance is strongly influenced by its paste additives composed of lead oxide, sulfuric acid, water, and carbon/oxide additives. The chemical and physical properties of the active material which is dictated by the additives must be capable of meeting the charge and discharge capacity. The technical challenge to be met in maximizing the capacity involves the improvement of charge acceptance and cycleability by increasing the conductivity and surface area of the negative electrode $[5,6]$.

Several studies have shown that the PbSO4 buildup on negative electrode can be dramatically reduced by introduction of carbon on the negative active layer [7-10]. The influence of the carbon additives on the electrochemical performance of $\mathrm{Pb}$-acid battery is governed by their material characteristics such as average particle size, total surface area and electrical conductivity. Reports of Pavlov [7, 8] shows that the addition of Carbon Black into the negative active layer have improvements on battery performance during the simulated electrical test. Reports of Baca[9] and Fernandez [10]reported that the addition of Graphite and Graphite-Carbon combinations into the negative electrode have significant beneficial effects on the capacity and cyle life of $\mathrm{Pb}$-acid battery.

Selection of different additives on the negative electrode is time consuming and expensive exercise as it is usually evaluated at battery level which includes battery making and testing. Electrochemical techniques such as Cyclic Voltammetry (CV), Potentiodynamic Polarization (PP), and Electrochemical Impedance Spectroscopy (EIS) performed at electrochemical cell level can deliver faster and accurate information for the operation performance of the negative electrode.

Corresponding author: ${ }^{\mathrm{a}}$ mat_fernandez04@yahoo.com, ${ }^{\mathrm{b}}$ francis_mulimbayan@yahoo.com, ${ }^{\mathrm{c}}$ lito.mena@nxp.com 
Electrochemical techniques will help for rapid evaluation and selection of different additives and can be the basis for defining reliable method of additive selection [11].

This research aims to determine the influence and mechanism of different carbon materials (Carbon black and Graphite) as additives on the negative electrode of $\mathrm{Pb}$-acid battery to improve its charge acceptance and cycleability. The electrode was characterized through electrochemical cellusing Cyclic Voltammetry, Potentiodynamic Polarization, and Electrochemical Impedance Spectroscopy. The data gathered from this research will contribute to the development of carbon and oxide as additives to the negative electrode of $\mathrm{Pb}$-acid battery, and for the development of electrochemical techniques in the selection of appropriate additives to the negative electrode of $\mathrm{Pb}$-acid battery.

\section{Cyclic Voltammetry: The effect of different carbon additives on the $\mathrm{Pb}$ electrode.}

The cyclic voltammographs of $\mathrm{Pb}$ and $\mathrm{Pb}+\mathrm{Carbon}$ electrodes after 100 cycles are presented in Fig. 1A. The voltammographs for the $\mathrm{Pb}$ and $\mathrm{Pb}+$ Carbon electrodes reflect the electrochemical faradaic reactions of $\mathrm{Pb}$ oxidation and reduction of $\mathrm{PbSO} 4$ into $\mathrm{H} 2 \mathrm{SO} 4$ solution. The first peak (Peak A) correspond to the anodic process or the oxidation of $\mathrm{Pb}$ to $\mathrm{PbSO} 4$ which can be associated with the discharge process on negative electrode. The second peak (Peak B) correspond to the cathodic process or the electroreduction of $\mathrm{PbSO} 4$ to $\mathrm{Pb}$, which can be associated with the charge process.During the positive (anodic) potential scan, the current density increases due to the electrochemical reaction on the $\mathrm{Pb}$ electrode. $\mathrm{PbSO} 4$ layer forms on the electrode surface and a peak current appears in the current curve. The $\mathrm{PbSO} 4$ layer exerts a passivating effect in the electrode thus resulting to rapid decline of current density after the peak current. During the cathodic scan, the $\mathrm{PbSO} 4$ layer is reduced to $\mathrm{Pb}$, yielding a cathodic current. The cyclic voltammographobtained on $\mathrm{Pb}+\mathrm{Carbon}$ electrodes with different carbon additives are similar to those of a double layer capacitor. Electrical double layer capacitors are energy storage devices in which the charges are stored at the interface between the active surface and electrolyte. The electrolyte ions are electrostatically adsorbed on the surface of the carbon electrodes $[11,12]$ The addition of carbon to the $\mathrm{Pb}$ electrode resulted into pronounced anodic and cathodic curves which suggest that the quantity of electricity generated by $\mathrm{Pb}+$ Carbon electrodes is higher than the electricity generated by the $\mathrm{Pb}$ electrode alone. The carbon attached on the surface of $\mathrm{Pb}$ electrode served as current collector which increases the anodic and cathodiccurves by the order of 3 to $10 \mathrm{x}$ magnitude depending on the type of carbon additive.

The peak current density and capacities of anodic charge and cathodic charge of $\mathrm{Pb}+\mathrm{Carbon}$ electrodes with different different carbon additives is presented in Fig. 1B. Peak current density corresponds to the highest current on the cyclic voltammograph. Addition of carbon on the $\mathrm{Pb}$ electrode increased the peak current density of the anodic reaction which correlated to increase of the electron transfer during the electrochemical faradaic reactions of $\mathrm{Pb}$ oxidation and reduction of $\mathrm{PbSO} 4$ into $\mathrm{H} 2 \mathrm{SO} 4$ solution. Among all the carbon additives, the highest peak current density was obtained from the $\mathrm{Pb}+\mathrm{CB} 1$ while the lowest is from the $\mathrm{Pb}+\mathrm{G}$.

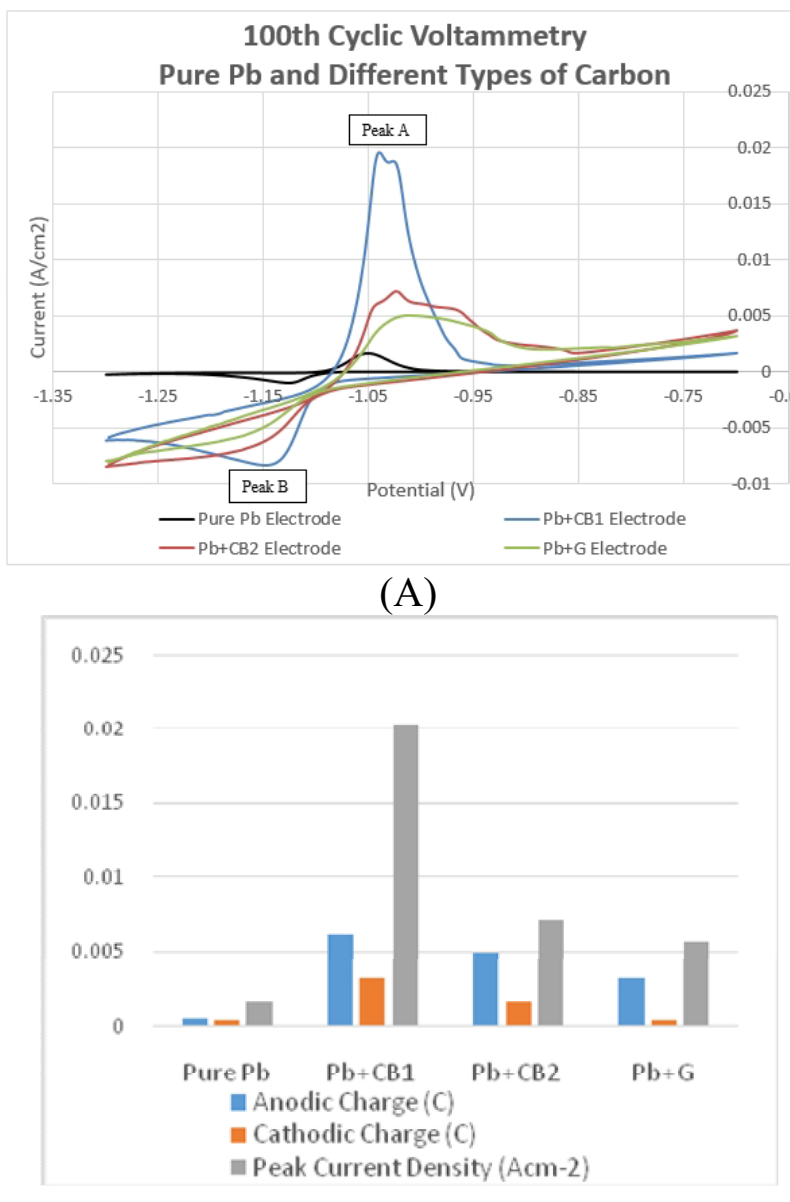

(B)

Figure 1. (A) $100^{\text {th }}$ cyclicvoltammograph of $\mathrm{Pb}$ and $\mathrm{Pb}+\mathrm{Carbon}$ electrodes. (B) Data deduced from the cyclic voltammograph.

The anodic and cathodic charge capacity of the additives were obtained by quantifying the anodic and cathodic total area of the 100thvoltammetric cycle. The increase of the anodic charge was attributed to the capacity of the $\mathrm{Pb}$ metal surface to form the $\mathrm{PbSO} 4$ passive layer. Anodic charge capacity corresponds to the anodic process and associated with the oxidation of $\mathrm{Pb}$ to $\mathrm{PbSO} 4$. Cathodic charge capacity corresponds to the cathodic process and associated with the reduction of $\mathrm{PbSO} 4$ to $\mathrm{Pb}$. Addition of carbon on the $\mathrm{Pb}$ electrode increased the anodic and cathodic charge capacity tenfold. The highest anodic and cathodic charge capacities were obtained on $\mathrm{Pb}+\mathrm{CB} 1$ electrodes while $\mathrm{Pb}+\mathrm{G}$ electrode has the lowest. The enhancement of the anodic and cathodiccharge capacity may suggest that the oxidation and reduction of $\mathrm{Pb}$ to $\mathrm{PbSO} 4$ proceeds on the $\mathrm{Pb}$ surface and also on the carbon layer which improves the capacity of charge and discharge of the $\mathrm{Pb}$ electrode $[11,12]$. 


\section{Potentiodynamic polarization: $\mathrm{PbSO} 4$ passivation rate of different carbon additives on the $\mathrm{Pb}$ electrode}

The kinetics of $\mathrm{PbSO} 4$ passivation was evaluated through the potentiodynamic polarization measurements. The rate of $\mathrm{PbSO} 4$ passivation of the different electrodes was calculated using the Butler-Volmer equation and Tafel constants. The potentiodynamic polarization curves of $\mathrm{Pb}$ and $\mathrm{Pb}+\mathrm{Carbon}$ electrodes are presented in Fig. 2 and the computed values were tabulated on Table 1. The addition of Carbon the $\mathrm{Pb}$ electrode shifted the Open Circuit Potential (OCP) into positive direction. OCP or sometimes called corrosion potential is the equilibrium potential of the metal when electrode is immersed on the electrolyte and not connected to any electrical system. $\mathrm{Pb}$ electrode has more negative OCP with average value of $1.055 \mathrm{~V}$. Addition of carbonadditives on the electrode shifted the OCP into more positive value (from $-0.267 \mathrm{~V}$ to $-0.151 \mathrm{~V}$ ) which may be attributed to the acceleration of the oxidation of $\mathrm{Pb}$ to $\mathrm{PbSO}$. Literature $[13,14]$ stated that the shifting of OCP into positive values favors the kinetics of the passive film growth or anodic reaction on metal active surfaces. The shifting of OCP values into positive direction is an indication of protective layer present on the metal active surface and indication of more stable metal surface. At higher OCP, the nucleation and growth process under charge transfer control favours the formation of more but smaller PbSO4crsytals [15]. Among all the $\mathrm{Pb}+$ Carbon electrodes, $\mathrm{Pb}+\mathrm{CB} 1$ has the highest (most positive) $\mathrm{OCP}$ values and $\mathrm{Pb}+\mathrm{G}$ has the lowest (more negative).

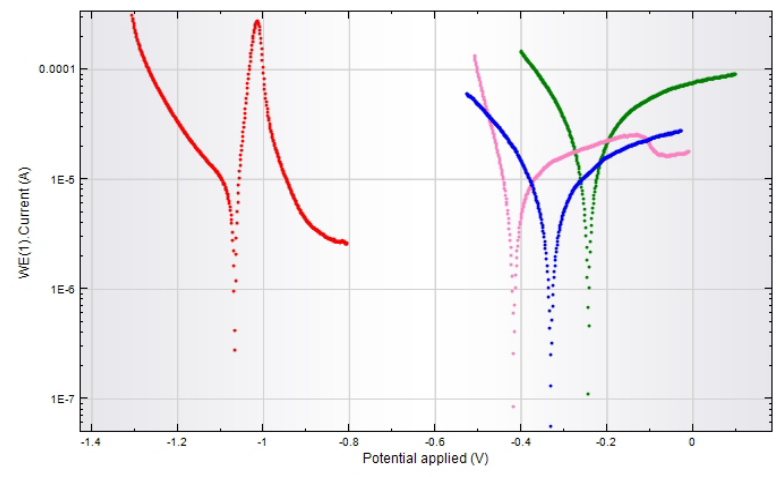

Figure 2. Linear polarization curves of the $\mathrm{Pb}+\mathrm{Carbon}$ electrodes.

Table 1. Computed values from the potentiodynamic polarization

\begin{tabular}{|c|c|c|c|c|c|c|}
\hline \multirow{4}{*}{$\begin{array}{c}\text { Elect } \\
\text { ode }\end{array}$} & \multicolumn{2}{|c|}{$\begin{array}{c}\text { OCP } \\
(\mathbf{V})\end{array}$} & \multicolumn{2}{c|}{$\begin{array}{c}\text { Passivation } \\
\text { Rate (mm/yr) }\end{array}$} & $\begin{array}{c}\text { Passivation } \\
\text { Density } \\
\left(\boldsymbol{\mu} \mathbf{A} / \mathbf{c m}^{2}\right)\end{array}$ \\
\cline { 2 - 7 } & Mean & Sdev & Mean & $\begin{array}{c}\text { Sde } \\
\mathrm{V}\end{array}$ & $\begin{array}{c}\text { Mean } \\
\text { Sde } \\
\mathrm{V}\end{array}$ \\
\hline $\begin{array}{c}\mathrm{Pure} \\
\mathrm{Pb}\end{array}$ & -1.055 & 0.001 & 0.82 & $\begin{array}{c}0.12 \\
5\end{array}$ & 13.79 & 2.1 \\
\hline $\begin{array}{c}\mathrm{Pb}+\mathrm{C} \\
\mathrm{B} 1\end{array}$ & -0.151 & 0.003 & 10.81 & $\begin{array}{c}0.33 \\
9\end{array}$ & 181.3 & 5.6 \\
\hline $\begin{array}{c}\mathrm{Pb}+\mathrm{C} \\
\mathrm{B} 2\end{array}$ & -0.188 & 0.006 & 4.91 & 0.63 & 82.47 & $\begin{array}{c}10 . \\
7\end{array}$ \\
\hline
\end{tabular}

\begin{tabular}{|c|c|c|c|c|c|c|}
\hline $\mathrm{Pb}+\mathrm{G}$ & -0.267 & 0.014 & 2.749 & 1.16 & 46.08 & $\begin{array}{c}19 . \\
52\end{array}$ \\
\hline
\end{tabular}

The results of potentiodynamic polarization showed that the $\mathrm{Pb}$ electrode has passivation rate of $0.82 \mathrm{~mm} / \mathrm{yr}$ and passivation current density of $13.79 \mu \mathrm{Acm}-2$. Same range of corrosion rate and corrosion density were reported by several authors on $\mathrm{Pb}$ electrode [16]. Addition of carbon into the $\mathrm{Pb}$ electrodes increased the rate of $\mathrm{PbSO} 4$ formation up to $\mathrm{x} 10$ magnitude. $\mathrm{Pb}+\mathrm{CB} 1$ electrode has the highest value of passivation rate and passivation current density which suggest that the $\mathrm{Pb}+\mathrm{CB} 1$ electrode has the greatest tendency to form $\mathrm{PbSO} 4$ passivation than the rest of the carbon electrodes. Several literaturesshowed that the fine $\mathrm{Pb}$ surface, having increased in active sites, favored the formation of the $\mathrm{PbSO} 4$ passive film than the coarse $\mathrm{Pb}$ surface [14-16]. Addition of carbon on the $\mathrm{Pb}$ active surface increased the active sites and current collection which favored the formation of $\mathrm{PbSO} 4$ passive film.

\section{Electrochemical impedance spectroscopy: $\mathrm{PbSO} 4$ passivation rate of different carbon additives on the $\mathrm{Pb}$ electrode}

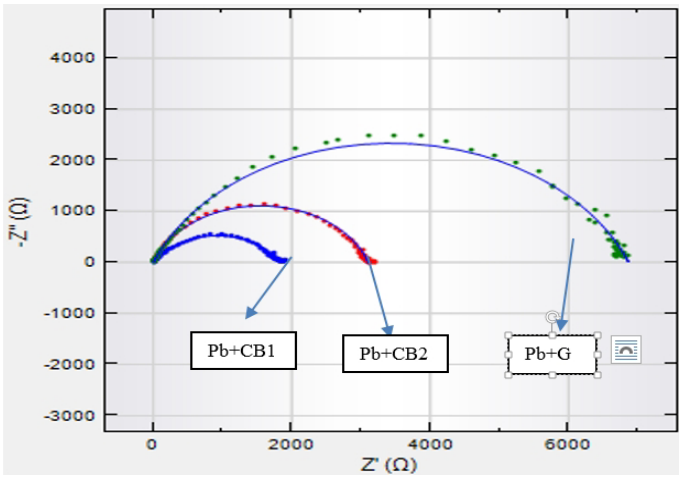

(A)

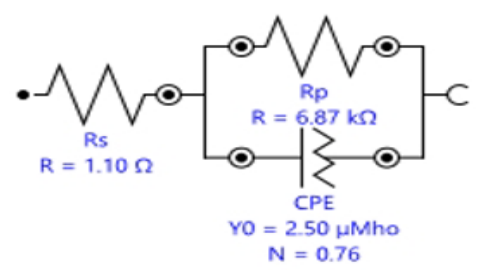

(B)

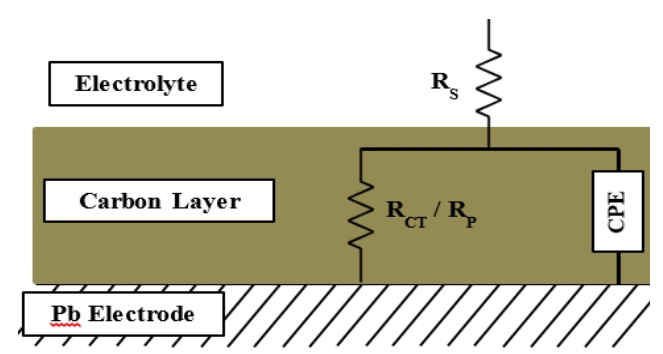

(C)

Figure 3. (A)Impedance spectra of the electrodes.

(B)Equivalent circuit model. (C)Physical model of the electrode. 
Table 2. Parameters deduced from the Impedance spectra.

\begin{tabular}{|c|c|c|r|r|r|r|}
\hline & \multicolumn{2}{|c|}{ Pb+CB1 Electrode } & \multicolumn{1}{c|}{ Pb+CB2 Eectrode } & \multicolumn{2}{c|}{ Pb+G Electrode } \\
\hline Element & Value & \% Error & \multicolumn{1}{c|}{ Value } & \multicolumn{1}{c|}{ \% Error } & \multicolumn{1}{c|}{ Value } & \multicolumn{1}{c|}{ \% Error } \\
\hline $\mathrm{R}_{\mathrm{S}}$ & 1.05 & 3.993 & 2.4275 & 3.366 & 3.1031 & 3.202 \\
\hline $\mathrm{R}_{\mathrm{P}} / \mathrm{R}_{\mathrm{CT}}$ & 1846 & 0.132 & 3105.5 & 0.255 & 6867.5 & 0.544 \\
\hline $\mathrm{CPE}$ & $1.17 \mathrm{E}-05$ & 1.534 & $2.21 \mathrm{E}-06$ & 1.28 & $2.50 \mathrm{E}-06$ & 2.114 \\
\hline$\chi^{2}$ & 0.0502 & & 0.023 & & 0.093 & \\
\hline
\end{tabular}

The Nyquist plot of the different $\mathrm{Pb}+\mathrm{Carbon}$ electrodes is presented in Fig. 3A. The Nyquist plot for the $\mathrm{Pb}+\mathrm{Carbon}$ electrodes have semicircular shape which suggest that the electrochemical mechanism and reaction kinetics is under charge-transfer or activation control which dictated by the rate of charge or electron flow [17-19]. The equivalent circuit model and the physical model of the electrode surface for different $\mathrm{Pb}+\mathrm{Carbon}$ electrodes is presented in Fig. 3B and Fig. 3C, respectively. The elements in the model will be the basis of the various phenomena going on at the interface. Based from the Fig. $3 \mathrm{C}, \mathrm{RP}$ or RCT is a measure of the charge transfer resistance of the carbon layer, $\mathrm{CPE}$ reflects the existence of capacitance or the charge stored in the carbon layer, and $\mathrm{RS}$ is a measure of the electrolyte resistance or resistance of the layer to current flow. Table 2 summarizes the parameter values obtained from the Nyquist plot and equivalent circuit of $\mathrm{Pb}+\mathrm{Carbon}$ electrodes. Among all the carbon additives, $\mathrm{Pb}+\mathrm{CB} 1$ electrode has the lowest RS and RCT while $\mathrm{Pb}+\mathrm{G}$ has the highest. Low RS and RCT mean fast faradaic reaction and the layer is conductive [17-19]. The CPE value for $\mathrm{Pb}+\mathrm{CB} 1$ electrode is higher than the $\mathrm{Pb}+\mathrm{CB} 2$ and $\mathrm{Pb}+\mathrm{G}$ electrode which agree with the capacitor-like behavior of the $\mathrm{Pb}+$ Carbonvoltammograph previously.

The enhancements upon addition of carbon additives on the $\mathrm{Pb}$ electrode were attributed with additive's electrical conductivity and total surface area. Carbon Black 1 having the highest electrical conductivity and finest particle size, resulted into more enhanced anodic and cathodic reactions by tenfold. The electrochemical active sites for the $\mathrm{PbSO} 4$ to nucleate and spread increases upon addition of electrical conductive and high surface area carbon additives.

\section{References}

1. D. Berndt, Journal of Power Sources, 100, 2946(2010)

2. Nakamura, Journal of Power Sources, 59, 153157(1996)

3. P. T. Moseley, JPS 127, 27-32 (2004)

4. Rand, Moseley, Garche, Parker, Valve regulated lead acid batteries, Elsevier (2004)

5. C. Snyders, Nelson Mandela Metropolitan University (2001)

6. United Nations Environment Programme (UNEP): Hybrid Electric Vehicles, UNEP (2009)

7. Pavlov, Nikolov, Rogachev, Petkova, JPS 191, 5878

8. Pavlov, Nikolov, Rogachev, JPS 196, 51555167(2011)

9. Baca, Micka, Krivik, Tonar, Toser, Journal of Power Sources 196, 3988-3992 (2011)

10. Fernandez, Valenciano, Trinidad, Munoz, JPS 195, 4458-4469 (2010)

11. Pavlov, Nikolov, Rogachev, JPS 195, 4444-4457 (2010)

12. Francia, Maja, Spinelli, JPS 95, 119-124 (2001)

13. C. E. Cerdan, E. B.Tamarit, D. M. Garcia, J. Anton, A. Bachir, J Electrochem Sci 7, 5754 (2012)

14. F. K. Sahrani, M. Aziz, Z. Ibrahim, A. Yahya, Sains Malaysiana 37, 359-364 (2008)

15. J. R. Vilche, F. E.Varela, JPS 64, 39-45 (1997)

16. R. Francia, M. Mena, Electrochemical corrosion of $\mathrm{Pb}-\mathrm{Ca}-\mathrm{Sn}$ alloy DMMME, UP (2005)

17. J. R. Davis, Surface Engineering for Corrosion and Wear Resistance, USA: ASM (2001)

18. A. J. Bard, Electrochemical Methods: Fundamentals and Applications, Wiley (2000)

19. S. Turgoose, Mater. Sci. Forum 269-280 (1992) 